\title{
Spleen contraction elevates hemoglobin concentration at high altitude during rest and exercise
}

\author{
Erika Schagatay ${ }^{1,2}\left(\right.$ Alexander Lunde $^{1} \cdot$ Simon Nilsson $^{1} \cdot$ Oscar Palm $^{1} \cdot$ Angelica Lodin-Sundström $^{1,3}$
}

Received: 2 October 2019 / Accepted: 10 August 2020 / Published online: 10 September 2020

(c) The Author(s) 2020

\begin{abstract}
Purpose Hypoxia and exercise are known to separately trigger spleen contraction, leading to release of stored erythrocytes. We studied spleen volume and hemoglobin concentration $(\mathrm{Hb})$ during rest and exercise at three altitudes.

Methods Eleven healthy lowlanders did a 5-min modified Harvard step test at 1370, 3700 and $4200 \mathrm{~m}$ altitude. Spleen volume was measured via ultrasonic imaging and capillary $\mathrm{Hb}$ with Hemocue during rest and after the step test, and arterial oxygen saturation $\left(\mathrm{SaO}_{2}\right)$, heart rate (HR), expiratory $\mathrm{CO}_{2}\left(\mathrm{ETCO}_{2}\right)$ and respiratory rate (RR) across the test.

Results Resting spleen volume was reduced with increasing altitude and further reduced with exercise at all altitudes. Mean (SE) baseline spleen volume at $1370 \mathrm{~m}$ was $252(20) \mathrm{mL}$ and after exercise, it was $199(15) \mathrm{mL}(P<0.01)$. At $3700 \mathrm{~m}$, baseline spleen volume was $231(22) \mathrm{mL}$ and after exercise $166(12) \mathrm{mL}(P<0.05)$. At $4200 \mathrm{~m}$ baseline volume was $210(23) \mathrm{mL}$ and after exercise $172(20) \mathrm{mL}(P<0.05)$. After $10 \mathrm{~min}$, spleen volume increased to baseline at all altitudes (NS). Baseline $\mathrm{Hb}$ increased with altitude from $138.9(6.1) \mathrm{g} / \mathrm{L}$ at $1370 \mathrm{~m}$, to $141.2(4.1)$ at $3700 \mathrm{~m}$ and $152.4(4.0)$ at $4200 \mathrm{~m}(P<0.01)$. At all altitudes $\mathrm{Hb}$ increased from baseline during exercise to $146.8(5.7) \mathrm{g} / \mathrm{L}$ at $1370 \mathrm{~m}, 150.4(3.8) \mathrm{g} / \mathrm{L}$ at $3700 \mathrm{~m}$ and $157.3(3.8) \mathrm{g} / \mathrm{L}$ at $4200 \mathrm{~m}$ (all $P<0.05$ from baseline). Hb had returned to baseline after $10 \mathrm{~min}$ rest at all altitudes (NS). The spleen-derived $\mathrm{Hb}$ elevation during exercise was smaller at $4200 \mathrm{~m}$ compared to $3700 \mathrm{~m}(P<0.05)$. Cardiorespiratory variables were also affected by altitude during both rest and exercise.

Conclusions The spleen contracts and mobilizes stored red blood cells during rest at high altitude and contracts further during exercise, to increase oxygen delivery to tissues during acute hypoxia. The attenuated $\mathrm{Hb}$ response to exercise at the highest altitude is likely due to the greater recruitment of the spleen reserve during rest, and that maximal spleen contraction is reached with exercise.
\end{abstract}

Keywords High altitude $\cdot$ Hematocrit $\cdot$ Hemoconcentration $\cdot$ Spleen volume $\cdot$ Spleen size

Communicated by I. Mark Olfert.

Erika Schagatay

Erika.Schagatay@miun.se

Alexander Lunde

Sweden.alex29@gmail.com

Simon Nilsson

simon16nilsson@gmail.com

Oscar Palm

Oscar.palm.92@gmail.com

Angelica Lodin-Sundström

Angelica.Lodin-Sundstrom@miun.se

1 Department of Health Sciences, Mid Sweden University, 83125 Östersund, Sweden

2 Swedish Winter Sports Research Centre, Mid Sweden University, Östersund, Sweden

3 Department of Nursing Sciences, Mid Sweden University, Sundsvall, Sweden

\author{
Abbreviations \\ AMS Acute mountain sickness \\ $\mathrm{ETCO}_{2}$ End-tidal carbon dioxide \\ $\mathrm{Hb}$ Hemoglobin concentration \\ HR Heart rate \\ RR Respiratory rate \\ $\mathrm{SaO}_{2} \quad$ Arterial oxygen saturation
}

\section{Introduction}

Spleen contraction with release of stored erythrocytes resulting in elevation of the circulating red blood cell volume occurs in various situations and species, including humans (Stewart and McKenzie 2002). This response has been observed in humans during exercise (Laub et al. 1993), exposure to apnea (Schagatay et al. 2001; Bacovic et al. 2003; Richardson et al. 2005) or a hypoxic environment (Richardson et al. 2008). While hypoxia is known to be 
an important trigger of spleen contraction (Richardson et al. 2009) it is further enhanced by the hypercapnia developing during apnea (Richardson et al. 2012), resulting in a more powerful contraction during apnea compared to simulated high altitude despite similar levels of hypoxia (Lodin-Sundström and Schagatay 2010). The spleen has sympathetic innervation and contraction is likely resulting from both neural input and catecholamine release (Stewart and McKenzie 2002), and the contraction was shown to be active, rather than due to a passive collapse (Bacovic et al. 2003).

Spleen function as a dynamic red blood cell reservoir is well described during apneic diving, but less studied at high altitude. Spleen contraction was first observed after diving shifts in professional Ama breath-hold divers (Hurford et al. 1990). The progressive elevation of hemoglobin concentration $(\mathrm{Hb})$ resulting from spleen contraction across serial apneas was found to prolong apneic duration in intact subjects while this response was not found in splenectomized subjects (Schagatay et al. 2001). In another study, spleen volume was found to correlate with competitive apneic diving performance in elite freedivers (Schagatay et al. 2012). Spleens were also larger in professional Bajau breath-hold divers, than in a non-diving population (Ilardo et al. 2018), which is functionally logical as the increase in circulating $\mathrm{Hb}$ will increase blood gas storage capacity as well as carbon dioxide buffering, both contributing to prolonged apneic duration. The decrease in spleen volume typically increases the total amount of circulating erythrocytes by 3-6\% with individuals responding with up to $10 \%$ increases (Richardson et al. 2008). This natural blood-boosting was also found to be active during exercise in chronically hypoxic patients with chronic obstructive pulmonary disease (COPD), where the most hypoxic patients were found to have the largest spleens and the most pronounced spleen contractions with exercise (Schagatay et al. 2015).

After maximal spleen contraction, it takes approximately 10 min before the spleen red cell supply is re-stored and the spleen has expanded to the resting volume (Schagatay et al. 2005). The spleen function as a dynamic red cell reservoir will not only transiently increase oxygen storage and delivery during exercise or hypoxic exposure, but lower blood viscosity between bouts of exercise or severe hypoxia and thereby reduce the sheer stress and thereby the work of the cardiovascular system (Schagatay et al. 2015).

As one of the major stimuli initiating spleen contraction is hypoxia, it is evident that spleen contraction could occur and be beneficial also at high altitude, especially during bouts of exercise leading to aggravated hypoxia. A study suggesting that spleen contraction occurs at high altitude was an observation of $\mathrm{Hb}$ increase across apneas at high altitude in a group of three climbers, a response that diminished with increasing altitude (Richardson and Schagatay 2007). However, actual spleen contraction at high altitude has up to now not been observed. Aiming to study this possibility, a recent study using handgrip exercise to induce spleen contraction found an effect on low altitude but not at high altitude, and the hematological response resulting from spleen contraction at low altitude was also absent at high altitude (Purdy et al. 2018). This seems to contradict the finding in a longitudinal study that spleen contraction during apnea and exercise was enhanced after a climb to the summit of Mt Everest (Engan et al. 2014), suggesting an important role of the spleen at altitude. It was also recently observed that elite high altitude climbers, going to the summit of Mount Everest at $8848 \mathrm{~m}$, had larger spleens than trekkers to Mount Everest Base Camp at $5300 \mathrm{~m}$ (Schagatay et al 2020).

While this hypoxia-induced mechanism would thus likely be beneficial for high altitude performance, and has been demonstrated to occur at simulated high altitude (Richardson et al. 2008), there is incomplete understanding of if, when and to what extent this response is actually present at high altitude. Our aim was, therefore, to reveal if spleen contraction and $\mathrm{Hb}$ elevation occur at high altitude, if this response is enhanced during whole-body exercise at high altitude, and whether the response is affected by the altitude.

\section{Methods}

\section{Participants}

Based on power calculations on the studied variables, the aim was to include $N \geq 10$ participants in the analysis. This suggested that at least 12 participants should be recruited, to allow some loss due to causes such as illness. Twelve healthy lowlanders (six men and six women) were recruited among university students planning a trek to $4200 \mathrm{~m}$ altitude in the Nepali Himalayas. They volunteered to participate in this study without benefits or payment, and knowing they could withdraw at any time without consequences. One woman did not complete all tests, and was excluded from the analysis. Mean (SD) anthropometric data for the remaining 11 subjects were age 26 (9) years, height $177(10) \mathrm{cm}$ and weight $71(10) \mathrm{kg}$, and BMI 22.8 (2.1). Vital capacity was $5.1(1.3) \mathrm{L} ; 107.5$ (10.7)\% of predicted; men 6.02 (0.9) L; 107.4 (13.9)\% of predicted and women $4.0(0.3) \mathrm{L}$; $107.5(6.6) \%$ of predicted. Men were taller $[184(5) \mathrm{cm}]$ and heavier [79 (5) kg] than the women [167 (5) cm; and $63(8)$ $\mathrm{kg}$ ], respectively $(P<0.01)$, and had larger lungs $(P<0.001)$, but there were no other differences between the sexes.

Participants were given a written and oral description of the procedures and potential risks involved, after which they signed a consent form. They also filled out a medical questionnaire, and all were to their own knowledge healthy. The study protocol had been approved by the Regional Committee for Medical and Health Research Ethics in Umeå, Sweden 
(Dnr: 2011-454-31M) and the Nepali Health Research Council (NHRC; Ref. No. 1079), and it complied with the 2004 Declaration of Helsinki. Baseline testing at a lowest altitude was done in Kathmandu at 1370 m, as this was where all the participants gathered before starting the trek.

\section{Procedures}

The measurements were conducted in the field during the first part of a longer trek in Rolwaling in the Nepali Himalayas at three different altitudes: Kathmandu 1370 m; Beding $3700 \mathrm{~m}$ and Naa, $4200 \mathrm{~m}$ above sea level (Fig. 1). During day 2 in Kathmandu, anthropometric data were collected and previous and recent history of altitude was noted. None of the subjects had been above $3000 \mathrm{~m}$ during the last 3 months. During the camping trek, each new altitude was reached in the evening, and one night was spent at that altitude after which the trek continued in the morning, except at the altitudes for measurements, where 2-3 days were spent (Fig. 1). The trek involved 5-8 h of trekking per day except testing days, carrying 14-18 kg per participant. The main part of the cargo: equipment necessary for camping, cooking, food and materials for measurements were carried by 45 porters. No participant took any drugs against symptoms of acute mountain sickness (AMS) during the study period and participants were asked to fill out the Lake Louise selfassessment protocol (LLQ) every morning for symptoms of AMS (Roach et al 1993).

The first exercise test was done in Kathmandu on day 3 after arrival and on the other locations, testing was done during the second day at that altitude, after arriving in the evening and sleeping one night (Fig. 1). Testing started in the early morning and was carried out in the same individual order at each location. Measurements of one subject took approximately $30 \mathrm{~min}$. The subjects did not eat or drink for at least $1 \mathrm{~h}$ prior to testing. To detect any dehydration, a morning urine sample of $30 \mathrm{ml}$ was collected in a white cup and the color of the urine compared with a color chart graded 1-8, where 1-3 is normal and 4-8 dehydrated. The chart is commonly used and acceptable to estimate dehydration in field conditions (Shirreffs 2000). No one was considered dehydrated during the days of testing.

\section{Exercise test}

A modified Harvard step test was used for the exercise test because it was considered to mimic daily motion patterns and would be easily repeatable for all subjects at all altitudes, is simple to standardize at different locations and because no heavy equipment is needed. The test started with the participant resting for $10 \mathrm{~min}$ in an upright position, while measurement probes were applied. Five minutes before the exercise test minute by minute measurements of spleen volume started and heart rate (HR), arterial oxygen saturation $\left(\mathrm{SaO}_{2}\right)$, end tidal alveolar carbon dioxide $\left(\mathrm{ETCO}_{2}\right)$ and respiratory rate $(\mathrm{RR})$ were recorded continuously. Approximately $1 \mathrm{~min}$ before the subject started to exercise, a capillary blood sample on the finger was taken for hemoglobin concentration ( $\mathrm{Hb})$. Directly after blood sampling, the subject stood up and remained standing for $1 \mathrm{~min}$ while listening to a metronome ticking at 1-s interval, the rhythm used when stepping up and down a box with a height of $31 \mathrm{~cm}$. The subject stepped up and down for $5 \mathrm{~min}$ and changed starting leg on a signal after 2.5 min. During the exercise, no spleen or blood measurements were done. After

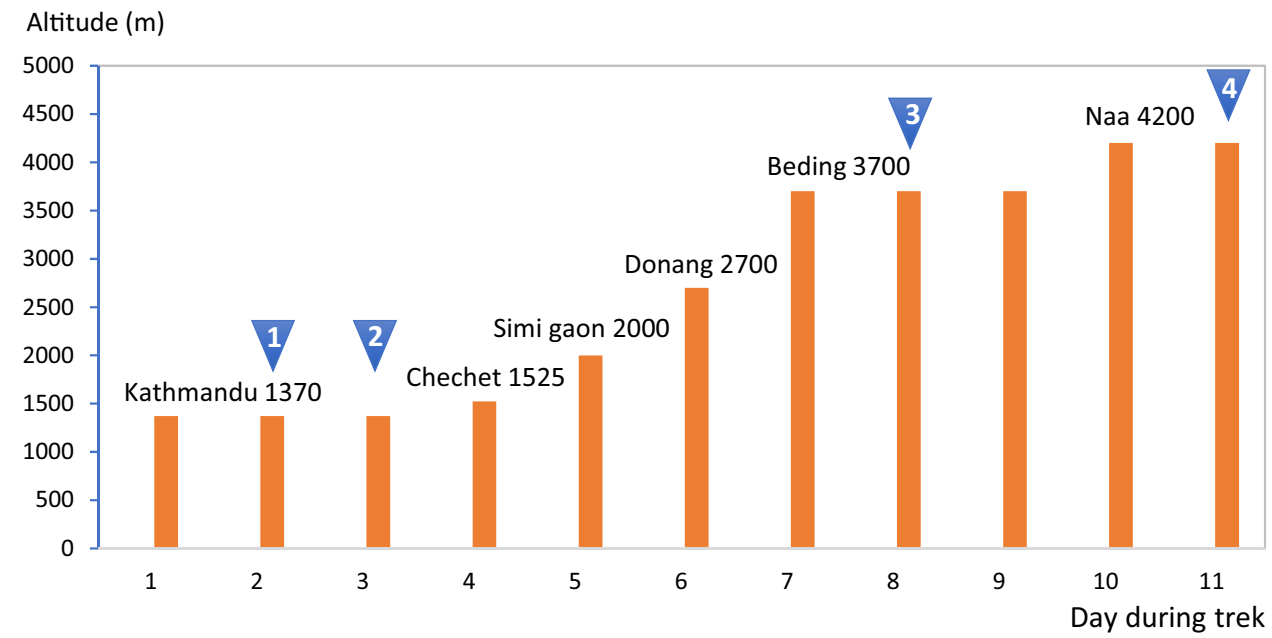

Fig. 1 The field measurements were conducted during 10 days at three different locations in the Rolwaling valley in the Nepali Himalayas. All subjects followed the same ascent profile. Altitudes for the locations where participants slept are shown. Arrows mark measurement days; 1: collection of background data and 2: step test in Kathmandu; 3: step test in Beding; 4: step test in Naa 
the exercise, the subject sat down and immediately a second capillary blood sample was taken and measurements of the spleen started and continued at 1-min intervals for $10 \mathrm{~min}$ during recovery. After 10 min of post-exercise rest, a third capillary blood sample was collected.

\section{Measurements}

The spleen measurements during $5 \mathrm{~min}$ prior to exercise, and $10 \mathrm{~min}$ after the step test was done with a portable ultrasonic imager (M-Turbo ultrasound system, FUJIFILM Sono Site Inc, Bothell, WA, USA), with the probe C60x/5-2 MHz (Transcluser Sono Site Inc, Bothell, WA, USA). Two pictures were taken every minute for determining the threeaxial maximal diameters of the spleen for length $(L)$, thickness $(T)$, and width $(W)$. These values were used to calculate the total spleen volume using the equation $L \pi\left(W T-T^{2}\right) / 3$, developed by Pilström (Schagatay et al. 2005).

The capillary finger blood samples for $\mathrm{Hb}$, taken $1 \mathrm{~min}$ before exercise, directly after exercise, and after $10 \mathrm{~min}$ of rest were collected in triplicate in microtainer cuvettes, and analyzed directly in a portable hemoglobin analyzer (Hemocue AB, Ängelholm, Sweden).

Cardiorespiratory variables: $\mathrm{HR}, \mathrm{SaO}_{2}, \mathrm{ETCO}_{2}$ and $\mathrm{RR}$ were measured continuously across the exercise test using a combined pulse-oximeter and capnograph (Medair Lifesense LS1-9R, Nonin Medical Inc, Medair AB, Hudiksvall, Sweden) and stored in a memory unit (Trendsense, Nonin Medical Inc, Medair AB, Hudiksvall, Sweden). The pulse-oximetry sensor was placed on the subjects' middle finger and a sampling hose for respiratory variables was placed under the subjects' nose.

\section{Analysis}

Mean baseline spleen volumes during the 5-min periods preceding the exercise test were compared between altitudes. For spleen contraction during exercise, the first post-exercise volume and the last value of $10 \mathrm{~min}$ of rest after the step test were compared to the last value during rest before the exercise. For $\mathrm{Hb}$, individual means of the three samples were used, and pre- and post-exercise and post-rest values were compared. Cardiorespiratory variables compared were mean values collected during the last minute of sitting rest, the last minute of exercise, and the last minute of the $10 \mathrm{~min}$ post-exercise rest. Subjects served as their own controls. One subject could not keep the stepping pace with the metronome during the last minute at the highest altitude, but the test was completed and peak values were included. Baseline variables and responses were compared between sexes. There were no differences found in any of the studied variables and, therefore, all subjects were treated as one group. All 11 subjects were included in all measurements, except in $\mathrm{RR}$ recordings, where one subject lacked data for the main part of the test, and was excluded from RR - analysis at all altitudes, thus $\mathrm{RR}$ values are based on $n=10$ subjects. The LLQ score from 3 days in the testing locations Beding at $3700 \mathrm{~m}$ and 3 days in Naa at $4200 \mathrm{~m}$, including the first days of exposure to the respective altitudes, were used to calculate a mean individual score, which was analyzed for correlation with measured variables.

Statistical analysis was done using ANOVA followed by Student's paired $t$ tests. Baseline values for spleen volume and $\mathrm{Hb}$ were compared between altitudes using a univariate one-way repeated measures ANOVA. Similarly, withinlocation values for exercise-induced spleen volume and $\mathrm{Hb}$ changes were compared using one-way repeated measures ANOVA. To assess the interaction between altitude (independent variable) and exercise (independent variable) on spleen contraction (dependent variable) and $\mathrm{Hb}$ change (dependent variable), a two-way repeated measures ANOVA was conducted. Simple main effects was assessed using separate one-way repeated measures ANOVAs with post hoc test using Bonferroni adjustment for multiple comparisons to assess for significant differences. Pearson's correlation analysis was used for correlation analysis. G power (3.0.10) was used to calculate observed power for selected variables. Significant difference was accepted at $P<0.05$.

\section{Results}

\section{Spleen volume}

Mean (SE) baseline spleen volume during the last 5-min rest preceding the exercise test was $252(20) \mathrm{mL}$ at $1370 \mathrm{~m}$, and it was subsequently reduced with increasing altitude, to 231 (22) $\mathrm{mL}$ at $3700 \mathrm{~m}(P<0.05$, power $=0.74)$ and $210(23) \mathrm{mL}$ at $4200 \mathrm{~m}(P<0.01$, power $=0.53$, compared to $1370 \mathrm{~m}$; $P=0.124$, power 0.12 , compared to $3700 \mathrm{~m}$; Figs. 2 and 3). After the step test, spleen volume had decreased at all altitudes, to 199 (15) $\mathrm{mL}$ at $1370 \mathrm{~m}$ (by $53 \mathrm{~mL} ; 21 \%), 166$ (12) $\mathrm{mL}$ at $3700 \mathrm{~m}$ (by $65 \mathrm{~mL} ; 28 \%$ ), and 172 (20) $\mathrm{mL}$ at $4200 \mathrm{~m}$ (by $38 \mathrm{~mL}$; $18 \%$; all $P<0.05$, (power $=0.99,1.00$ and 0.99 , respectively) compared to baseline; Figs. 2 and 3). Post-exercise volumes did not differ between altitudes (NS, power $=0.71-0.99$ ). Changes in volumes with exercise were $52(14) \mathrm{mL}$ at $1370 \mathrm{~m}$, $64(19) \mathrm{mL}$ at $3700 \mathrm{~m}$ and $38(12) \mathrm{mL}$ at $4200 \mathrm{~m}(P=0.158$ from $3700 \mathrm{~m}$, power 0.82 ; Fig. 5). Neither were there any significant differences between altitudes in the relative changes (NS).

During the 10-min period of rest after exercise, spleen volume gradually increased back to baseline levels at all altitudes (all NS from baseline values; Fig. 2). At $10 \mathrm{~min}$, it was $273(23)$ at $1370 \mathrm{~m}, 247(31)$ at $3700 \mathrm{~m}(P=0.329$, power $=0.98$ from $1370 \mathrm{~m}$ ), and $200(24) \mathrm{mL}$ at $4200 \mathrm{~m}$ $(P<0.001$, power $=0.99$ from $1370 \mathrm{~m} ; P=0.097$, power 0.99 from 3700 m; Fig. 3). 
Fig. 2 Mean (SE) spleen volume across the exercise test at 3 altitudes for 11 participants. Difference between the last minute value during rest and first value after exercise is indicated by $* P<0.05$ and $* * P<0.01$

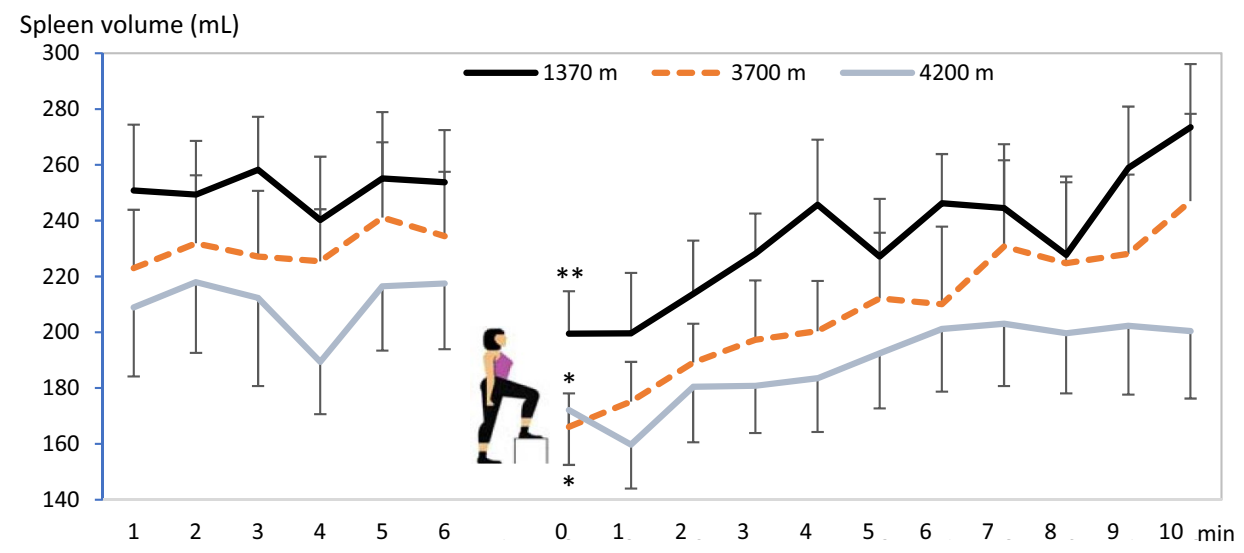

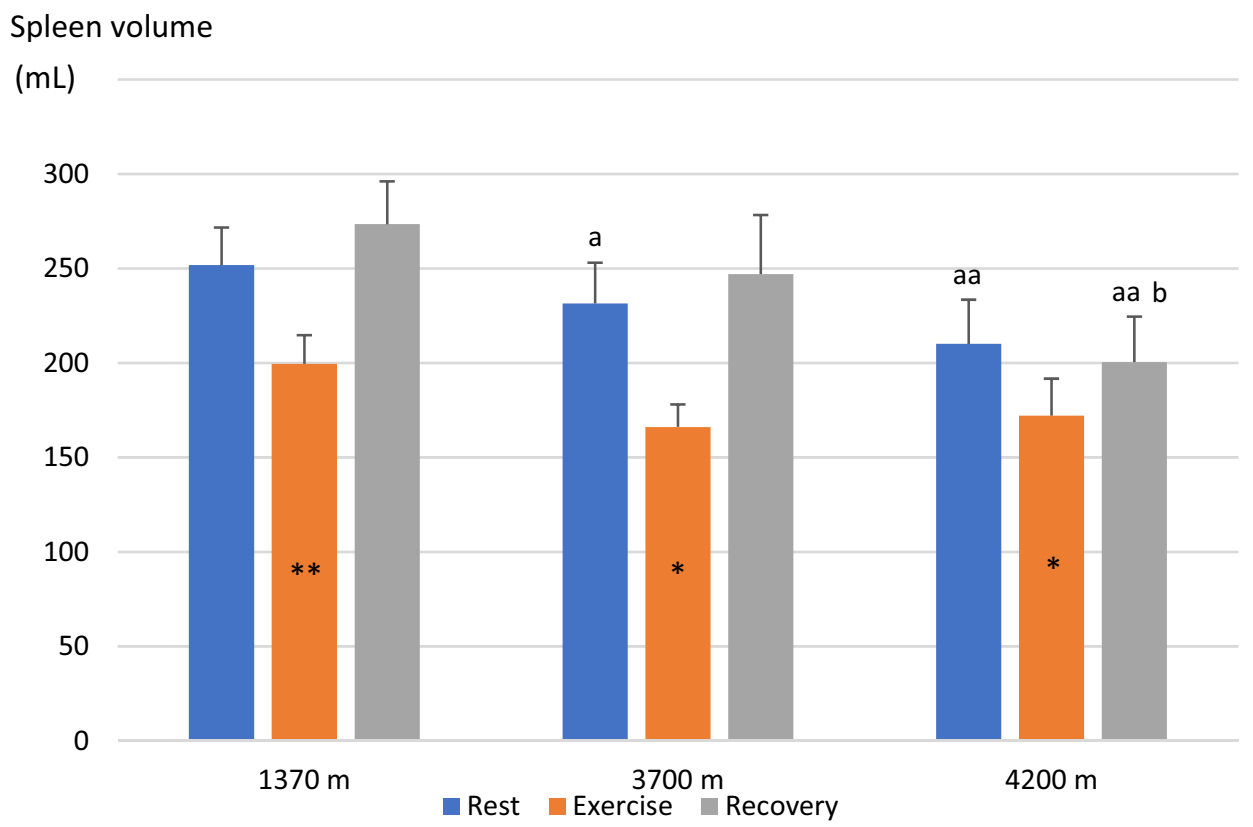

Fig. 3 Mean (SE) spleen volumes during 5-min rest before step test, directly after the 5-min step test, and after 10-min rest at 3 altitudes for 11 participants; Kathmandu $1370 \mathrm{~m}$, Beding $3700 \mathrm{~m}$ and Naa $4200 \mathrm{~m}$. Significant difference between baseline value and first post-exercise value within altitudes is indicated with $* * P<0.01$ and $* P<0.05$. At 10 min post-exercise, spleen volumes were back to

\section{Hemoglobin concentration}

Mean (SE) baseline $\mathrm{Hb}$ after 10 min rest before exercise progressively increased with increasing altitude, from $138.9(6.1) \mathrm{g} / \mathrm{L}$ at $1370 \mathrm{~m}$, to $141.2(4.1)$ at $3700 \mathrm{~m}$ $(\mathrm{NS}$, power $=0.99)$ and $152.4(4.0)$ at $4200 \mathrm{~m}(P<0.05$, power $=0.99$ to $1370 \mathrm{~m} ; P<0.001$, power $=0.99$ to $3700 \mathrm{~m}$; Fig. 4). After the step test, Hb had increased from baseline at all altitudes, to $146.8(5.7) \mathrm{g} / \mathrm{L}$ at $1370 \mathrm{~m}$ (by $7.9 \mathrm{~g} / \mathrm{L} ; 5.7 \% ; P<0.001$, power $=0.46$ ), $150.4(3.8)$ $\mathrm{g} / \mathrm{L}$ at $3700 \mathrm{~m}($ by $9.2 \mathrm{~g} / \mathrm{L} ; 6.5 \% ; P<0.01$, power $=0.99)$ baseline at all altitudes (all NS). Differences between baseline volumes at Kathmandu and other altitudes is indicated with a above columns (a for $P<0.05$; aa for $P<0.01$ ). There was no difference between Beding and Naa for rest and exercise (NS). Post-exercise volumes were different between Beding and Naa (b for $P<0.05$ )

and $157.3(3.8) \mathrm{g} / \mathrm{L}$ at $4200 \mathrm{~m}$ (by $4.9 \mathrm{~g} / \mathrm{L} ; 3.2 \% ; P<0.05$, power $=0.96$; Fig. 4$)$. The spleen-derived $\mathrm{Hb}$ elevation during exercise was attenuated at $4200 \mathrm{~m}$ compared to $3700 \mathrm{~m}$, both as absolute values $(P<0.05$, Fig. 5$)$. and as relative increase in $\mathrm{Hb}(P<0.05$, power $=0.79)$.

After 10 min post-exercise rest, $\mathrm{Hb}$ had returned to baseline at all altitudes (all NS from baseline; Fig. 4) and was $134.4(6.7) \mathrm{g} / \mathrm{L}$ at $1370 \mathrm{~m}, 143.3(4.3) \mathrm{g} / \mathrm{L}$ at $3700 \mathrm{~m}$ $(\mathrm{NS}$, power $=0.99$ from $1370 \mathrm{~m})$ and $152.5(4.3) \mathrm{g} / \mathrm{L}$ at $4200 \mathrm{~m}(P=0.073$, power $=1.00$ from $1370 \mathrm{~m} ; P<0.05$, power $=0.99$ from $3700 \mathrm{~m}$; Fig. 4). 
Fig. 4 Mean (SE) hemoglobin concentration $(\mathrm{Hb})$ during rest before exercise, during the last minute of the step test, and $10 \mathrm{~min}$ after exercise for 11 participants at 3 altitudes; in Kathmandu 1370 m, Beding $3700 \mathrm{~m}$ and Naa $4200 \mathrm{~m}$. Significant difference between baseline value and first postexercise value within altitudes is indicated with $* * P<0.01$ and $* P<0.05$. At 10 min postexercise, spleen volumes were back to baseline at all altitudes (all NS). Differences between baseline volumes at Kathmandu and other altitudes are indicated with a above columns for $P<0.05$. There was also a difference between Beding and Naa for exercise and post-exercise volumes (b for $\mathrm{P}<0.05$; bbb for $P<0.001)$

Fig. 5 Mean (SE) change from baseline in spleen volume and hemoglobin concentration $(\mathrm{Hb})$ at three altitudes; $1370 \mathrm{~m}, 3700 \mathrm{~m}$ and $4200 \mathrm{~m}$.

Values are means from 11 participants. Significant difference between $\mathrm{Hb}$ elevation at 3700 and $4200 \mathrm{~m}$ is indicated by $* P<0.05$, while other differences were not significant. $P$ value for spleen volume comparison between 3700 and $4200 \mathrm{~m}$ is shown above column
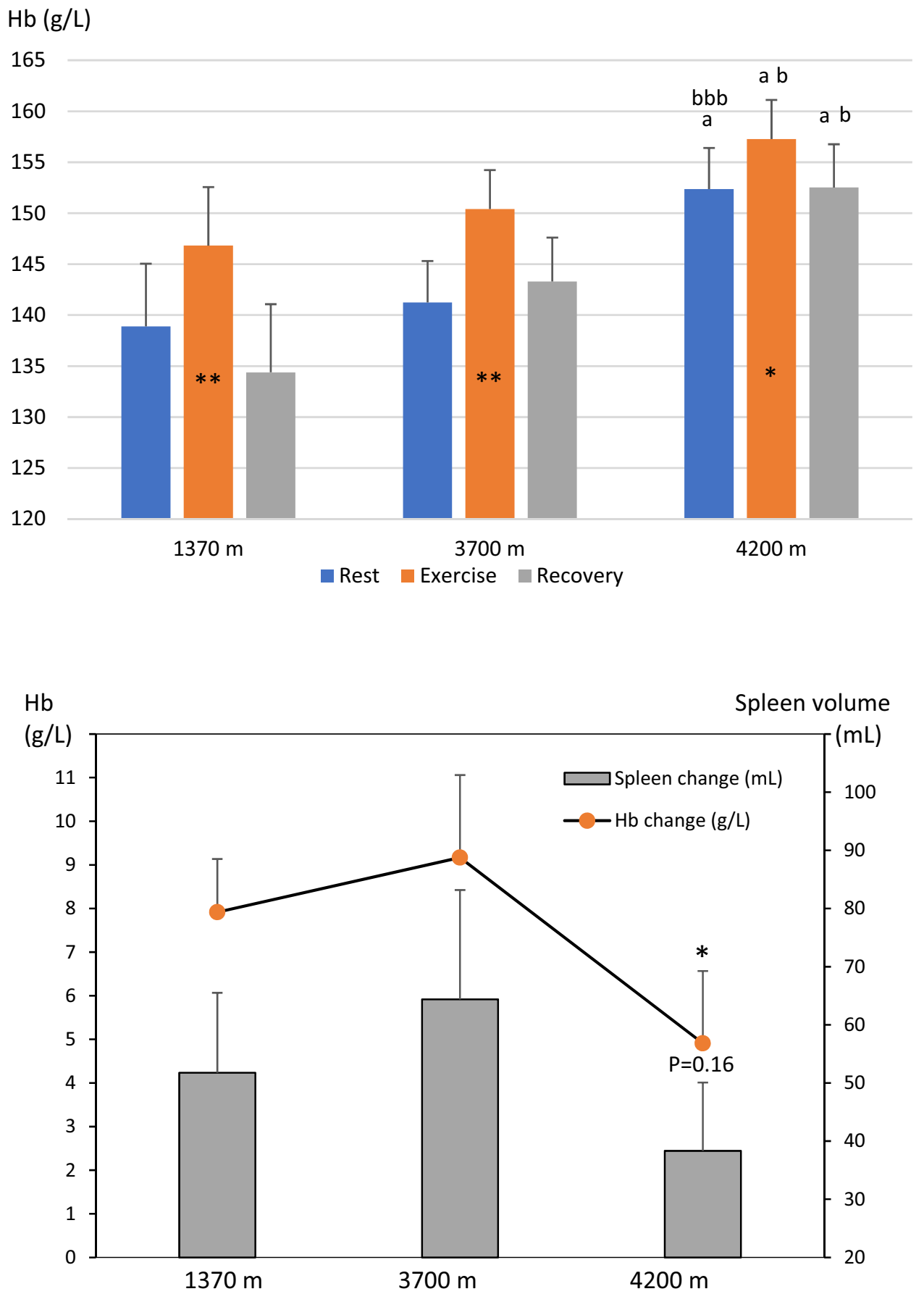

\section{Association between spleen volume and hemoglobin concentration}

Correlation analysis revealed that baseline values of spleen volume and $\mathrm{Hb}$ were positively associated, both as individual values $(r=0.442 ; P<0.05)$ and for individual mean values for all altitudes $(r=0.667 ; P<0.05)$. When altitudes were analyzed separately there was an association found at $1370 \mathrm{~m}$ $(r=0.622)$ and $3700 \mathrm{~m}(r=0.771$; both $P<0.05)$, but not at
$4200 \mathrm{~m}$ ( $r=0.402$; NS), where spleen volume had decreased and $\mathrm{Hb}$ increased as a response to the increased altitude.

\section{Cardiorespiratory variables}

Cardiorespiratory variables: $\mathrm{HR}, \mathrm{SaO}_{2}, \mathrm{ETCO}_{2}$ and RR were also generally affected by the altitudes, both at rest and during exercise (Fig. 6). Baseline $\mathrm{SaO}_{2}$ was clearly lower at the higher altitudes, and exercise lead to a further aggravation 

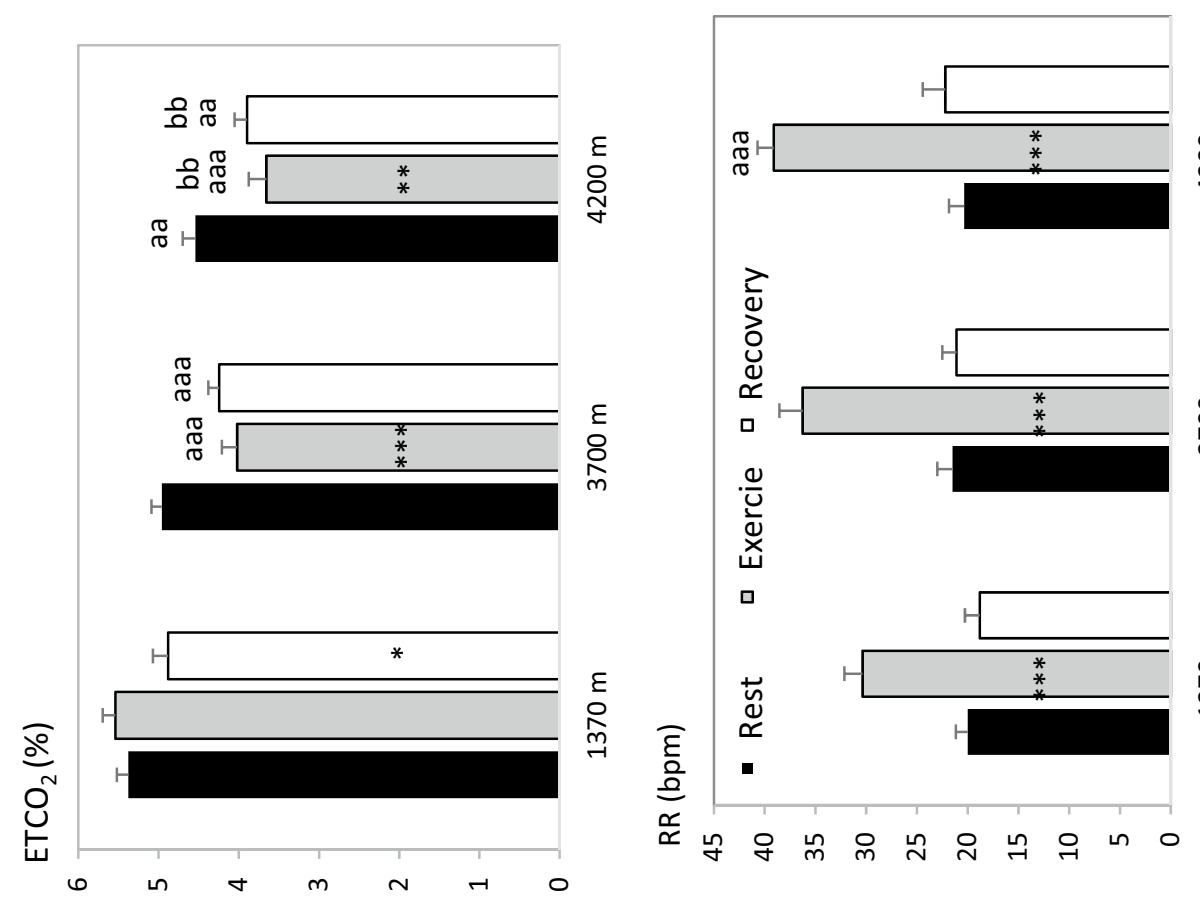

호요월

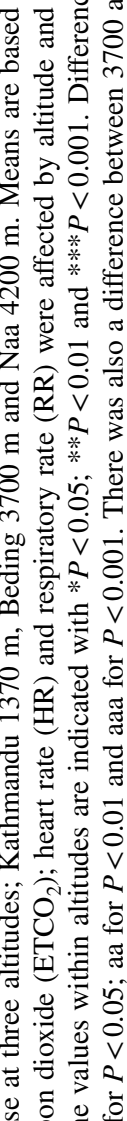
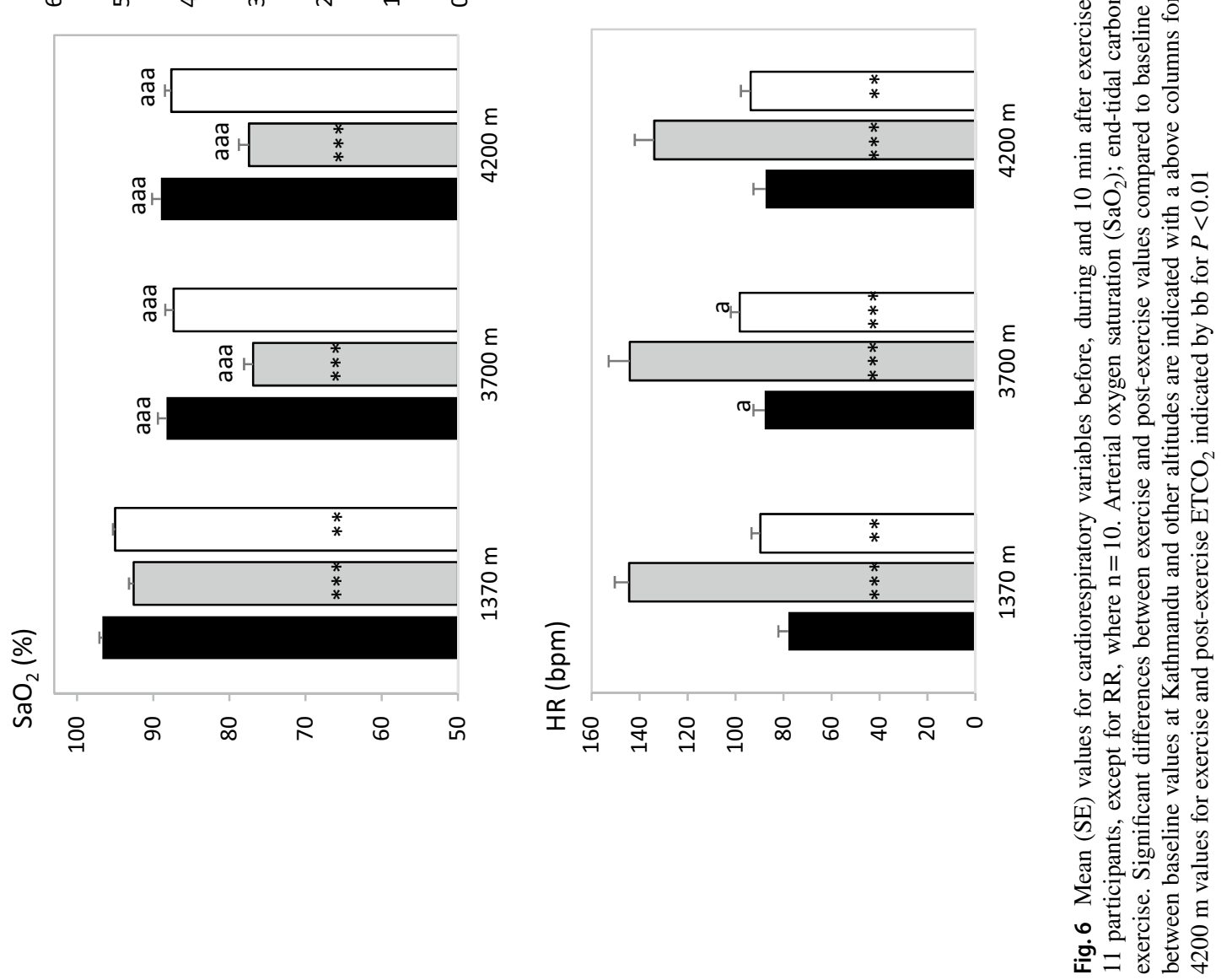
of the hypoxia at all altitudes, an effect that was more pronounced with higher altitudes (Fig. 6a). Baseline $\mathrm{ETCO}_{2}$ was also lower with higher altitudes relating to the hypoxiatriggered increased respiration, as seen in the increased RR. While there was no effect of exercise on $\mathrm{ETCO}_{2}$ directly after exercise at $1370 \mathrm{~m}(\mathrm{NS})$, it was lowered after $10 \mathrm{~min}$ recovery (Fig. 6b). Exercise led to a further reduction in $\mathrm{ETCO}_{2}$ at the higher altitudes that remained after $10 \mathrm{~min}$ recovery (Fig. 6b). Baseline and recovery HR were higher at $3700 \mathrm{~m}$ than at $1370 \mathrm{~m}$, and exercise increased HR at all altitudes (Fig. 6c). RR was increased at $4200 \mathrm{~m}$ compared to $1370 \mathrm{~m}$, and increased as a result of exercise at all altitudes (Fig. 6d).

\section{Acute mountain sickness symptoms}

None of the subjects were suffering from AMS during the trek. Eight subjects completed the LLQ, five male and three female. Among these subjects, the daily scores during the 6 days at 3700 and $4200 \mathrm{~m}$ ranged between 0 and 2 (mean 1.15). The baseline spleen volume and $\mathrm{Hb}$ did not correlate with LLQ scores, neither did their changes during exercise correlate with LLQ scores (NS). HR, $\mathrm{ETCO}_{2}$ and RR showed no correlation with the LLQ, but the $\mathrm{SaO}_{2}$ during the step test at $3700 \mathrm{~m}$ and $4200 \mathrm{~m}$ showed a correlation with the LLQ score $(r=-0.84 ; P<0.01$, power $=0.74)$. No correlation was identified between $\mathrm{SaO}_{2}$ and spleen- or $\mathrm{Hb}$ responses to exercise (NS).

\section{Discussion}

This study clearly shows that the spleen acts as a dynamic red blood cell reservoir at high altitude. Recruitment of part of the reservoir occurs already during rest at high altitude, and during exercise, the spleen has a capacity to expel a supplementary volume of red blood cells into circulation, to cope with the aggravated hypoxia. It is evident from the transient elevation of $\mathrm{Hb}$ that spleen contraction has an effect on circulating erythrocyte volume. The close association between $\mathrm{Hb}$ and spleen volume supports this conclusion. This is in line with previous observations of simultaneous spleen contraction and $\mathrm{Hb}$ elevation during apnea (Baković et al. 2005) and during simulated altitude by eupneic hypoxia during rest (Richardson et al. 2008), but it has never been observed at high altitude.

This is the first clear evidence from a field observation that the human spleen has an important role in adjusting circulating $\mathrm{Hb}$ to fit the demands to varying degrees of hypoxia at high altitude. In this way, the un-acclimatized climber will have a means to cope with hypoxia much earlier than if only the $\mathrm{Hb}$ elevation caused by enhanced erythropoiesis would be available, which takes at least a week to develop (West
2012). The main functional effect would be to enhance the capacity for blood oxygen storage and transportation (Schagatay et al 2001), with known benefits at high altitude (West 2012).

The maximal capacity for the spleen to contract seems to be reached already during exercise at $3700 \mathrm{~m}$, when the smallest volume of $166 \mathrm{~mL}$ is reached, and no further reduction is seen with exercise at the higher altitude $4200 \mathrm{~m}$, thus this volume may be the smallest possible volume for the spleen to reach when "empty". The largest volume observed, $273 \mathrm{~mL}$, suggests that an average volume of about $100 \mathrm{~mL}$ of concentrated blood can be expelled from the spleen, and with $\mathrm{a} \mathrm{Hb}$ about double that of the circulating blood (Laub et al., 1993; Stewart and McKenzie 2002) this would add the equivalent of the oxygen carrying capacity of an additional $200 \mathrm{~mL}$ of circulating blood. Based on an estimated blood volume in our group (Nadler et al. 1962), that would lead to an addition of approximately $4 \mathrm{~g} / \mathrm{L}$ of circulating $\mathrm{Hb}$. However, the maximum increase of $\mathrm{Hb}$ observed was about the double. There have been similar observations in other studies, e.g., by Richardson et al (2008) which concluded that the spleen contributed to $60 \%$ of the observed increase in hematocrit during hypoxic exposure. This suggests that other stagnant pools of erythrocytes may also be recruited, or that there was a shift in plasma volume induced, or possibly that the timing of the spleen volume and blood sampling was not synchronized with the minimum and maximum values, respectively.

The only previous observation of similar changes of this dynamic elevation of $\mathrm{Hb}$ with altitude was in a small study by Richardson et al. (2007) where it was discovered that the transient elevation in $\mathrm{Hb}$ during apnea at $1230 \mathrm{~m}$ was attenuated at $3840 \mathrm{~m}$ and eventually disappeared at $5100 \mathrm{~m}$. This attenuation of the $\mathrm{Hb}$ response when individuals traveled to progressively higher altitudes suggests that the spleen may eventually reach its maximally contracted state during rest at high altitude, which means it cannot produce any further $\mathrm{Hb}$ elevation despite an additional hypoxic stimulus (Richardson et al. 2007). On the descent from altitude, the $\mathrm{Hb}$ responses during apnea returned, and were greater in magnitude than that on the same altitude during the ascent, suggesting that acclimatization had abolished the need of a tonic contraction during rest (Richardson et al. 2007). Thus, the tonic spleen contraction during rest on ascent may be a means to cope with the chronic hypoxia before acclimatization leads to elevated $\mathrm{Hb}$ and makes other protective mechanisms available. After this initial stage, only the severe hypoxia related to exercise will lead to blood-boosting for transiently increasing the oxygen carrying capacity, a response that would likely be very beneficial for fine-tuning oxygen delivery across a longer exposure to high altitude hypoxia when the oxygen transport system is under stress. 
An enhancement of spleen function was found to be part of the acclimatization to hypoxia in rats (Kuwahira et al. 1999). Earlier studies on climbers found enhanced spleen contraction during exercise after long-term high-altitude exposure during an expedition summiting Mount Everest (Engan et al. 2014). In another group, trekking to less extreme altitude, it was observed that both spleen volume and contraction during exercise were enhanced on return to low altitude (Rodríguez-Zamora et al. 2015). The difference between the results in these two similar studies could possibly be caused by a general catabolism in the "Death Zone" above $8000 \mathrm{~m}$, not allowing spleen enlargement. It was also recently observed that top climbers had larger spleens and spleen contraction during apnea, compared to recreational high altitude trekkers (Schagatay et al. 2020). Taken together these studies suggest that also the spleen itself may be subject to altitude acclimatization, which is in line with the current study's observations of a significant spleen function in elevating $\mathrm{Hb}$ at altitude. Thus, the spleen may have two distinctive effects at high altitude: (1) to cope with the acute hypoxia in the un-acclimatized lowlander, before erythropoiesis has elevated $\mathrm{Hb}$ sufficiently to counteract it, and (2) a long-term effect increasing spleen volume and contractility with altitude exposure, as part of the acclimatization process, so that a larger dynamic red cell volume can be recruited by spleen contraction during exercise and stored away in the spleen during rest, to reduce blood viscosity.

Both our present study and the results cited above seem to be conflicting with a study by Sonmez et al (2007), in which it was reported that long-term exposure to high altitude in lowlanders resulted in reduced splenic volume and increased $\mathrm{Hb}$ across 6 months. In that time, substantial altitude acclimatization has elevated $\mathrm{Hb}$ via increased erythropoiesis, and it is not clear how this relates to the relatively short-term adjustments seen in the current study.

Our present results do not support the conclusions from the recent study by Purdy et al (2018) that the spleen does not mobilize erythrocytes during ascent to high altitude. In that study, baseline spleen volume was not found to differ between the altitudes $1045 \mathrm{~m}, 3440 \mathrm{~m}$, and $4240 \mathrm{~m}$, neither did the spleen contract as a stress response to handgrip exercise at high altitude (Purdy et al. 2018). In the same study, spleen contraction was seen at all altitudes on injection of phenylephrine hydrochloride, and the authors concluded that the spleen does not contribute to acclimatization to high-altitude hypoxia, due to alterations in spleen reactivity to increased sympathetic activation at altitude (Purdy et al. 2018). The spleen is mainly innervated by sympathetic nerves with both $\alpha$ - and $\beta$-adrenoceptors (Ayers et al. 1972) and spleen contraction can probably be induced by both neural input and catecholamine release (Stewart and McKenzie 2002). While resting spleen volumes observed by Purdy et al (2018) at $1045 \mathrm{~m}(273 \mathrm{~mL})$, were similar to what we observed at $1370 \mathrm{~m}(252 \mathrm{~mL})$, their handgrip exercise at $1045 \mathrm{~m}$ only caused a spleen contraction of $8 \%$, while in our study, the step test caused a $21 \%$ spleen contraction. Likewise, the Hct in their study increased from baseline by $4 \%$, while in our study, by $6 \%$. This suggests that the handgrip exercise is not as powerful a stimulus as the exercise with large muscle groups causing aggravated hypoxia during step test in our study. Furthermore, in the study by Purdy et al (2018), the shrinkage of the spleen observed after phenylephrine infusion could be caused by eliciting spleen vasoconstriction, thus by a different mechanism than the physiological neural stimulation. There could also be other vascular responses from injection of the phenylephrine bolus, e.g., overstimulation of the baroreceptors, which could have blunted the endogenous sympathetic activity. Therefore, we consider the study by Purdy et al. (2018) inconclusive of whether spleen contraction occurs during exercise at high altitude. Their lack of effect of altitude on resting spleen volume remains contrasting to our observations. Purdy et al (2018) thus suggested that the constant spleen volume at different altitudes is a result of a decreased reactivity to sympathetic activity but while there may be a long-term downregulation of beta-adrenoreceptors with chronic hypoxia (Richalet et al 1988), this may not likely have developed in these relatively un-acclimatized subjects. While both the studies by Richardson et al. (2007) and Purdy et al (2018) may suggest that splenic reactivity was reduced at high altitude, the present study involving whole-body exercise induced a sufficient stressor to manifest as a powerful response also at high altitude. However, we suggest that the spleen response will likely reach a "roof" due to its anatomical properties, which appears to be the case at the highest altitudes.

The input responsible for spleen contraction in our study is most likely the hypoxia during rest and the aggravated hypoxia during whole-body exercise, in accordance with earlier findings (Richardson et al. 2008). Hypercapnia has also been found to trigger spleen contraction during apnea (Richardson et al. 2012) but would not likely be involved at high altitude due to the increased ventilation. In our study, the $\mathrm{RR}$ increased with increasing altitude and baseline $\mathrm{ETCO}_{2}$ was reduced, with further changes with exercise. Exercise in itself may have contributed as it has been found to directly induce spleen contraction (Laub et al. 1993; Stewart and McKenzie 2002).

An important role of the spleen as a dynamic red cell reservoir for predicting performance in apneic divers has been reported in several studies (Schagatay et al 2001; Bakovic et al. 2003; Schagatay et al 2012, Ilardo et al 2018) and we interpret from our current results that it could have the same role in humans exposed to high altitude. We recently reported a negative correlation between individual spleen volume during rest in Kathmandu at 1370 m and the 
incidence of symptoms of acute mountain sickness (AMS) in trekkers going to Mt Everest Base Camp $(P<0.05$; Holmström et al. 2019). However, in that study, the spleen contraction during apnea at $1370 \mathrm{~m}$ was not significantly associated with AMS symptoms $(P=0.121$; Holmström et al. 2019). It was however recently found that spleen baseline volume was greater in experienced mountaineers going to climb Mt Everest, than in Mt Everest Base Camp trekkers (Schagatay et al. 2020), suggesting that spleen function is important for successful climbing at high altitude. It was also recently reported that larger spleens and more powerful contractions were present in the Sherpa population of high altitude origin, compared to Nepali lowlanders (Holmström et al. 2020). A difference between Sherpas currently residing high and low, respectively, was also observed, suggesting that not only genetic factors but also exposure to hypoxia may determine spleen size (Holmström et al. 2020).

As an important step to understand spleen function at high altitude better, the current study shows that the spleen was more contracted during rest with higher altitudes, which was reflected by a progressively higher baseline $\mathrm{Hb}$. We, therefore, speculate that spleen contraction during rest could be responsible for at least part of the transient early elevation of $\mathrm{Hb}$ described previously, which has been attributed to a reduced plasma concentration due either to dehydration or hormonal changes at high altitude (reviewed by West 2012). We thus interpret our result as showing an alternative explanation for the phenomenon of early elevation of $\mathrm{Hb}$ in newcomers to altitude, at least in strong responders. The obvious benefit of the observed mechanism would be to fine-tune circulating $\mathrm{Hb}$ between the oxygen demands and the aim to reduce viscosity. Thus, $\mathrm{Hb}$ can be optimized between-on the one hand-enhanced oxygen demands with the more severe hypoxia with exercise and - on the other- that part of the red cell supply is stored in the spleen between bouts of exercise to reduce viscosity and thereby limit the strain on the cardiovascular system related to the polycythemia. This spleen-derived regulation of circulating $\mathrm{Hb}$ to meet the short-term demands could possibly allow more efficient use of the limited resources during the hypoxic stress at high altitude. This original finding suggests a possible mechanism whereby a large and contractile spleen could enhance high-altitude performance which should be further studied.

We suggest that the observed transient $\mathrm{Hb}$ elevation with spleen contraction during work at high altitude could help explain the association between individual spleen volume and AMS symptoms, as reported by Holmström et al (2019), although with our limited LLQ data we could not support this association. The correlation between LLQ score and $\mathrm{SaO}_{2}$ during exercise in our study, despite a limited sample, supports that people with high $\mathrm{SaO}_{2}$ may likely suffer less from AMS, in accord with several other studies (West 2012).

\section{Study limitations}

By necessity, a field study like this has restrictions on which laboratory equipment can be used, and has to rely on smaller monitors and often simpler methods than in a stationary laboratory, as all equipment has to be carried on the back to location, and the laboratory has to be rapidly mounted before tests can begin at every location. The data from the equipment in this study have, however, been compared to results obtained with more advanced monitors in stationary laboratories at high altitude (e.g., Holmström et al 2019) and been found to be in agreement.

Full measurements of minute ventilation and cardiac output would have been valuable. Measuring RR is not sufficient to determine ventilation, just as HR is not enough to determine cardiac output. However, these variables can give an indication of the effects of the regulatory influence of combined hypoxia and hypocapnia during exercise at high altitude. The $\mathrm{ETCO}_{2}$ was recorded in $\%$, while measurements using $\mathrm{mmHg}$ would have been more useful with respect to determining effects on cerebral blood flow.

We recruited 12 subjects from a trekking group consisting of 14 lowlanders, but drop-out is common in straining field conditions. After 1 of the subjects did not complete all tests, the number of subjects was 11 , which was just sufficient according to our power calculations prior to the expedition, and only 8 subjects filled out the LLQ self-assessment form. We believe that this limited sample does not allow negative conclusion on the correlation between spleen volume and physiological variables or LLQ. The small group studied is a limitation of this study.

\section{Conclusions}

We found that the spleen contracts during rest with increased altitude and mobilizes stored red blood cells, and suggest that this could be responsible for at least part of the transient early elevation in $\mathrm{Hb}$ often observed during ascent to high altitude. The baseline tonic contraction during rest could give the climber a faster access to elevated $\mathrm{Hb}$ than the erythropoiesis-derived increase occurring during acclimatization. The response could be important as a means to cope with high-altitude hypoxia, at least in strong responders.

When not fully contracted during rest, the spleen contracts further during exercise as a response to the aggravated hypoxia, which will increase oxygen delivery to tissues to cope with transient acute hypoxia. This response apparently fine-tunes circulating $\mathrm{Hb}$ by optimizing the level between requirements for sufficient oxygen delivery and reduced sheer stress to the circulatory system. This response likely helps the climber to manage oxygen supplies better. We suggest that the main factor initiating spleen contraction in 
both rest and exercise at high altitude is the severity of the hypoxia. Based on the current study and that of Richardson et al. (2007) we concluded that the response magnitude with aggravated hypoxia depends on the prior level of contraction during rest at a given altitude, and that $\mathrm{Hb}$ elevation is therefore attenuated at higher altitudes. We concluded that spleen function is important at high altitude and deserves further study.

Acknowledgements We thank the trekkers for participating in our study, and for giving us a hand with various tasks during the measurements. We also thank Mr Chhiring Sherpa and Mr Ngawang Sherpa for letting us build our lab in their father's houses in Beding and Naa, including temporarily removing the inner roof for space to make the step test, and the guides Mr Cyhote, Mr Lhakba Mr Ngome and $\mathrm{Mr}$ Cham for exceptional assistance during our expedition. We thank Dr Harald Engan, MSc Alexander Patrician and MSc Orio Johansson for help with expedition preparations and logistics. We further thank Prof. Dr Arjun Karki, Patan Academy, for valuable help and advice, and M.Sc. Pontus Holmström for help with statistics. Last but not least we thank all our porters, without whom this study had not been possible. The expedition was supported by the Swedish National Centre for Research in Sports (CIF) and the Swedish Winter Sports Research Centre (SWSRC) at Mid Sweden University.

Author contributions ES: idea, design, planned and lead the expedition, collected data in Nepal, analyzed data, and wrote the manuscript. AL, SN and OP: contributed to design, collected data in Nepal, analyzed data, and reviewed the manuscript. ALS contributed to the design and expedition planning, collected data in Nepal, analyzed data, and reviewed the manuscript.

Funding Open access funding provided by Mid Sweden University.

\section{Compliance with ethical standards}

Conflict of interest We declare that the research was conducted without any potential conflict of interest.

Open Access This article is licensed under a Creative Commons Attribution 4.0 International License, which permits use, sharing, adaptation, distribution and reproduction in any medium or format, as long as you give appropriate credit to the original author(s) and the source, provide a link to the Creative Commons licence, and indicate if changes were made. The images or other third party material in this article are included in the article's Creative Commons licence, unless indicated otherwise in a credit line to the material. If material is not included in the article's Creative Commons licence and your intended use is not permitted by statutory regulation or exceeds the permitted use, you will need to obtain permission directly from the copyright holder. To view a copy of this licence, visit http://creativecommons.org/licenses/by/4.0/.

\section{References}

Ayers AB, Davies BN, Withrington PG (1972) Responses of the isolated, perfused human spleen to sympathetic nerve stimulation, catecholamines and polypeptides. Br J Pharmacol 44:17-30

Baković D, Valic Z, Eterović D, Vuković I, Obad A, Marinović-Terzić I, Dujic Z (2003) Spleen volume and blood flow response to repeated breath-hold apneas. J Appl Physiol 95(4):1460-1466
Baković D, Eterovic D, Saratlija-Novakovic Z, Palada I, Valic Z, Bilopavlovic N, Dujic Z (2005) Effect of human splenic contraction on variation in circulating blood cell counts. Clin Exp Pharmacol Physiol 32:944-951

Engan HK, Lodin-Sundstrom A, Schagatay F, Schagatay E (2014) The effect of climbing Mount Everest on spleen contraction and increase in hemoglobin concentration during breath holding and exercise. High Alt Med Biol 15(1):52-57. https://doi.org/10.1089/ ham.2013.1061

Holmström P, Mulder E, Lodin-Sundström A, Limbu P, Schagatay E (2019) The magnitude of diving bradycardia during apnea at lowaltitude reveals tolerance to high altitude hypoxia. Front. Physiol. https://doi.org/10.3389/fphys.2019.01075

Holmström PK, Mulder ER, Starfelt V, Lodin-Sundström A, Schagatay E (2020) Spleen Size and Function in Sherpa Living High, Sherpa Living Low and Nepalese Lowlanders. Front Physiol. https://doi. org/10.3389/fphys.2020.00647

Hurford WE, Hong SK, Park YS, Ahn DW, Shiraki K, Mohri M, Zapol WM (1990) Splenic contraction during breath-hold diving in the Korean Ama. J Appl Physiol 69:932-936

Ilardo MA, Moltke I, Korneliussen TS, Cheng J, Stern AJ, Racimo F, Rasmussen S, van den Munckhiot ICL, Fer Host R, Joosten LAB, Netea MG, Salingkat S, Nielsen R, Willerslev E (2018) Physiological and genetic adaptations to diving in sea nomads. Cell 173(3):569-580

Kuwahira I, Kamiya U, Iwamoto T, Moue Y, Urano T, Ohta Y, Gonzalez NC (1999) Splenic contraction-induced reversible increase in hemoglobin concentration in intermittent hypoxia. J Appl Physiol 86(1):181-187. https://doi.org/10.1152/jappl.1999.86.1.181

Laub M, Hvid-Jacobsen K, Hovind P, Kanstrup I, Christensen NJ, Nielsen SL (1993) Spleen emptying and venous hematocrit in humans during exercise. J Appl Physiol 74(3):1024-1026

Lodin-Sundström A, Schagatay E (2010) Spleen contraction during 20 min normobaric hypoxia and $2 \mathrm{~min}$ apnea in humans. Aviat Space Environ Med 81(6):545-549

Nadler S, Hidalgo J, Bloch T (1962) Prediction of blood volume in normal human adults. Surgery 51:224-232

Purdy GM, James MA, Rees JL, Ondrus P, Keess JL, Day TA, Steinback CD (2018) Spleen reactivity during incremental ascent to altitude. J Appl Physiol 126(1):152-159

Richalet JP, Larmignat P, Rathat C, Keromes A, Baud P, Lhoste F (1988) Decreased cardiac response to isoproterenol infusion in acute and chronic hypoxia. J Appl Physiol 65:1957-1961

Richardson M, Schagatay E (2007) Altitude attenuates apnea-induced increase in haemoglobin concentration. In: 12th Internatiopnal Conference on Environmental Ergonomics (ICEE XII), Slovenia August $19-24,2007$

Richardson M, de Bruijn R, Holmberg HC, Björklund G, Haughey H, Schagatay E (2005) Increase of hemoglobin concentration after maximal apneas in divers, skiers, and untrained humans. Can J Appl Physiol 30(3):276-281

Richardson MX, Lodin-Sunström A, Reimers J, Schagatay E (2008) Short-term effects of normobaric hypoxia on the human spleen. Eur J Appl Physiol 104(2):395-399

Richardson MX, de Bruijn R, Schagatay E (2009) Hypoxia augments apnea-induced increase in hemoglobin concentration and hematocrit. Eur J Appl Physiol 105(1):63-68. https://doi.org/10.1007/s0042 1-008-0873-9

Richardson MX, Engan H, Lodin-Sundstrom A, Schagatay E (2012) Effect of hypercapnia on spleen-related haemoglobin increase during apnea. Undersea Hyp Med 42(1):4-9

Roach CR, Bartsch P, Hackett P, Oelz O (1993) The Lake Louise acute mountain sickness scoring system. Hypoxia Mol Med 4:272-274

Rodríguez-Zamora L, Lodin-Sundström A, Engan HK, Höök M, Patrician A, Degerström E, Schagatay E (2015) Effects of altitude acclimatization on spleen volume and contraction during 
submaximal and maximal work in lowlanders. Abstract, 20th European College of Sports Science (ECSS), Malmö, June 24-27, 2015

Schagatay E, Andersson J, Hallén M, Pålsson B (2001) Selected contribution: Role of spleen emptying in prolonging apneas in humans. J Appl Physiol 90(4):1623-1629

Schagatay E, Haughey H, Reimers J (2005) Speed of spleen volume changes evoked by serial apneas. Eur J Appl Physiol 93(4):447-452

Schagatay E, Richardson MX, Lodin-Sundstrom A (2012) Size matters: spleen and lung volumes predict performance in human apneic divers. Front Physiol 3:173. https://doi.org/10.3389/fphys .2012 .00173

Schagatay E, Hubinette A, Lodin-Sundström A, Stenfors N (2015) Spleen contraction and erythrocyte increase following exercise in subjects with COPD. COPD Res Pract. https://doi.org/10.1186/ s40749-015-0015-9

Schagatay E, Holmström P, Mulder E, Limbu P, Schagatay FS, Engan H, Lodin-Sundström A (2020) Spleen volume and contraction during apnea in Mt. Everest Climbers and Everest Base Camp Trekkers. High Alt Med Biol 21(1):84-91. https://doi.org/10.1089/ ham.2019.0028

Shirreffs SM (2000) Markers of hydration status. J Sports Med Phys Fit 40(1):80-84

Sonmez G, Ozturk E, Basekim CC, Mutlu H, Kilic S, Onem Y, Kizilkaya E (2007) Effects of altitude on spleen volume: sonographic assessment. J Clin Ultrasound 35(4):182-185

Stewart IB, McKenzie DC (2002) The human spleen during physiological stress. Sports Med 32(6):361-369

West JB (2012) High-altitude medicine. Am J Resp Critical Care Med 186(12):1229-1237

Publisher's Note Springer Nature remains neutral with regard to jurisdictional claims in published maps and institutional affiliations. 